\title{
Inhibitors of apoptosis protect the ovarian reserve from cyclophosphamide
}

\author{
Yi Luan', Maxwell E Edmonds'1, Teresa K Woodruff' ${ }^{1}$ and So-Youn Kim,2 \\ 1Division of Reproductive Science in Medicine, Department of Obstetrics and Gynecology, Feinberg School of Medicine, Northwestern University, Chicago, \\ Illinois, USA \\ 2Olson Center for Women's Health, Department of Obstetrics and Gynecology, and Fred \& Pamela Buffett Cancer Center, University of Nebraska Medical \\ Center, 985860 Nebraska Medical Center, Omaha, Nebraska, USA
}

Correspondence should be addressed to S-Y Kim: soyoun.kim@unmc.edu

\begin{abstract}
Cancer therapy can cause off-target effects including ovarian damage, which may result in primary ovarian insufficiency in girls and premenopausal women. Loss of ovarian follicles within the ovarian reserve leads to ovarian endocrine dysfunction and impaired fertility. Cyclophosphamide (CPA), a commonly used chemotherapeutic and immunosuppressant agent, is a gonadotoxic agent that destroys ovarian cells by crosslinking DNA. To protect the ovary against CPA damage, we sought to precisely map the mechanism by which the ovarian reserve is depleted by CPA. We found that CPA specifically depletes primordial follicles without affecting primary and secondary follicles in three independent murine strains (CD-1, C57BL/6) and $\mathrm{BALB} / \mathrm{C} \mathrm{J})$ in vivo. We directly tested the effect of the active metabolite of CPA, $1 \mu \mathrm{M}$ 4-hydroxyperoxycyclophophamide (4-HC), in vitro and confirmed the loss of primordial oocytes but no change in the number of primary and secondary follicles. We demonstrated that phospho-AKT ( $p$-AKT) and cleaved PARP (CPARP) are present in primordial oocytes 3 days after CPA injection, consistent with the role of these markers as part of the apoptotic cascade. Interestingly, P-AKT positive primordial oocytes co-expressed cPARP. Treatment of animals with specific inhibitors of apoptotic pathway components, ETP46464 and CHK2, blocked 4-HC-induced DNA damage in vitro. These data suggest that CPA targets primordial germ cells in the ovarian reserve by stimulating apoptosis pathways. Adjuvant therapies to protect primordial germ cells from the off-target effects of CPA may reduce the risk of POI.
\end{abstract}

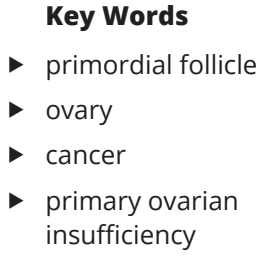

Journal of Endocrinology (2019) 240, 243-256

\section{Introduction}

In the mammalian ovary, the primordial follicle is a nongrowing, non-dividing oocyte surrounded by squamous granulosa cells that are not yet steroidogenic. The number of primordial follicles is established at birth and forms the ovarian reserve from which regular and reliable numbers of primordial follicles are activated throughout reproductive life and enter the pool of growing follicles to support endocrine function and fertility. The endocrine hormones produced by the growing follicles in the ovary are important for heart, bone and brain function and are critical for women's health. Advances in cancer treatments have improved survival rates, but have also revealed the consequences of off-target effects on long-term health and quality of life of cancer survivors. Chemotherapy and radiation therapy can cause irreversible damage to the ovary, leading to loss of ovarian follicles and premature 
ovarian insufficiency (Demeestere et al. 2012), reducing both reproductive potential and systemic endocrine support. Identifying the mechanisms by which cancer therapies cause ovarian follicle loss may lead to the development of preventive adjuvant therapies that can protect the ovary without altering the effects of the drug on the primary cancer.

CPA is a commonly used chemotherapy drug in cancer treatment for both solid and hematological malignancies, including breast cancer, bone cancer, soft tissue sarcomas, Hodgkin's and non-Hodgkin's lymphomas and leukemia (Petrillo et al. 2011). CPA is often the first-line treatment for patients with autoimmune diseases such as systemic lupus erythematosus (SLE) (Thorbinson et al. 2016). CPA has a range of off-target effects, including damage to the bladder, immunosuppression, alopecia and amenorrhea related to ovarian follicle depletion (Fraiser et al. 1991, Chemaitilly et al. 2006, Hudson 2010). CPA is activated by CYP2B and CYP3A to produce 4-hydroxycyclophosphamide (4-OH-CPA), which can be interconverted to aldophosphamide (AP). AP can be metabolized to phosphoramide mustard (PM) (Ludeman 1999), which causes rapid destruction of proliferating cells by inducing apoptotic pathways through DNA damage (Petrillo et al. 2011, Madden et al. 2014, Ganesan $\&$ Keating 2015). 4-HC is a congener of CPA that was first manufactured in the 1970s (Van der Steen et al. 1973, Takamizawa et al. 1975) and can be easily converted into the key metabolite 4-OH-CPA without an enzymatic reaction. It is transported much more readily into cells than ionic PM.

Previous research on the mechanism underlying oocyte loss after treatment with another chemotherapeutic agent, cisplatin (CDDP), identified a role for TAp63 $\alpha$ (Gonfloni et al. 2009, Kerr et al. 2012a, Kim et al. 2013, 2018). A member of the p53 family of proteins, TAp63 $\alpha$ is known to be a guardian of the genome, and is specifically expressed in female germ cells during early development and in follicles up to the early secondary stage (Kurita et al. 2005, Suh et al. 2006). In healthy primordial oocytes, TAp63 $\alpha$ remains in an inactive dimer form until phosphorylated by CHK2 and CK1 in response to DNA damage caused by CDDP or irradiation (Bolcun-Filas et al. 2014, Tuppi et al. 2018). Activation of TAp63 $\alpha$ induces the expression of BAX, which activates PUMA- and NOXA-dependent apoptosis in primordial oocytes (Kerr et al. 2012b). In contrast to CDDP, the mechanism by which CPA depletes the ovarian reserve is controversial, with some evidence that CPA directly damages primordial follicles and other evidence suggesting that $\mathrm{CPA}$ overactivates primordial follicles, thus indirectly reducing the number of follicles remaining in the ovarian reserve while increasing the number of primary and secondary growing follicles. The goal of this study was to clarify the effect of CPA on the primordial follicle pool and the mechanism by which CPA treatment leads to loss of the ovarian reserve.

\section{Materials and methods}

\section{Animals}

All procedures involving mice were approved by the Institutional Animal Care and Use Committee (IACUC) at Northwestern University. Three different strains of mice, ICR (CD-1 $\left.{ }^{\circledR}\right)$ (Harlan, Indianapolis, IN), C57BL/6J (000664, The Jackson Laboratory), and BALB/cJ (000651, The Jackson Laboratory) mice were obtained. Animals were treated at Northwestern University's Center of Comparative Medicine (Chicago, IL, USA) and were provided with food and water ad libitum. Temperature, humidity, and photoperiod (14h light $-10 \mathrm{~h}$ dark) were kept constant. A Hamilton Syringe (7637-01, Hamilton Company, Reno, NV, USA) with a 33-gauge needle (7803-05, Hamilton Company) was used to inject mice intraperitoneally (i.p.) with CPA (PHR1401, MilliporeSigma) or an equivalent volume of PBS (vehicle) at the following doses and times.

The three strains of mice were i.p. injected with $150 \mathrm{mg} / \mathrm{kg}$ CPA or vehicle at 8 weeks of age and ovaries were harvested $24 \mathrm{~h}$ post injection. In a second experiment, the three strains mice were injected on postnatal day 5 (PD5) with $150 \mathrm{mg} / \mathrm{kg}$ CPA or vehicle and the ovaries were collected at 1, 3, 7 or 14 days post injection. An additional group of 7-week-old CD-1 mice were i.p. injected with 75 or $200 \mathrm{mg} / \mathrm{kg}$ of CPA and the ovaries were harvested after 1 week. Another group of 4 -week-old CD-1 mice were i.p. injected with 75 or $150 \mathrm{mg} / \mathrm{kg}$ of CPA weekly for 4 weeks and ovaries were harvested 1 week after the final injection. All mice were i.p. injected with the same volumes of either PBS or CPA.

\section{Whole ovary organ culture}

Ovary organ culture was performed as previously described (Kim et al. 2013, 2015). Briefly, ovaries collected from PD5 mice were placed on Millicell inserts (PICM03050, EMD Millipore Co.) in 6-well or 12-well plates with $\alpha$-MEM (32561-037, Gibco, Thermo FisherScientific) supplemented with Probumin $(0.3 \%, 81-066-4$, MilliporeSigma) and ITS (1X from 100X stock, I3146, MilliporeSigma). 
4-HC (sc-206885, Santa Cruz Biotechnology, Inc., Dallas, TX), dissolved in DMSO (D2650, MilliporeSigma), was added to culture media to the final concentration. Inhibitors were added $2 \mathrm{~h}$ prior to the treatment with $2 \mu \mathrm{M} 4$-HC. The ovaries were incubated at $37^{\circ} \mathrm{C}$ under $5 \%$ $\mathrm{CO}_{2}$. The culture media was changed every $48 \mathrm{~h}$ with $4-\mathrm{HC}$ to the final concentration. The ovaries were harvested at various time points during culture and processed for histologic analysis, immunofluorescence (IF) or immunohistochemistry (IHC). The number of primordial follicles was determined and compared between treatment groups at $96 \mathrm{~h}$ because apoptosis by $4-\mathrm{HC}$ has been shown to occur within this time frame. The dose of 4-HC used in ovarian organ culture was based on toxicity data demonstrating induction of $>80 \%$ primordial follicle death within $96 \mathrm{~h}$ without damage to granulosa cells of secondary follicles or somatic cells. The catalog numbers and source of inhibitors were as follows: Chk2 inhibitor II hydrate (C3742) from MilliporeSigma; ETP-46464 (S8050) from Selleckchem (Houston, TX, USA).

\section{Follicle counting}

Ovaries were fixed in Modified Davidson's fixative (6413310, Electron Microscopy Sciences Inc., Hatfield, PA, USA) at $4^{\circ} \mathrm{C}$ for $24 \mathrm{~h}$ after in vitro culture or harvesting from mice, and processed into paraffin blocks. The blocks were sectioned in their entirety at $5 \mu \mathrm{m}$ thickness for H\&E staining, TUNEL, IF and IHC assays. H\&E staining was performed using standard methods. Primordial (PF), primary (PM) and secondary (SF) follicles were counted in every 10th section stained with H\&E (Kim et al. 2015). In order to determine the total number of primordial follicles per ovary, the average number of primordial follicles per section was multiplied by the total number of sections and divided by the average number of sections in which a single primordial follicle appeared. Then, the number was divided by two because the diameter of a primordial oocyte covers at least two sections (average primordial follicle number per section $\times$ total section number $\times 1 / 2$ ). The number of surviving primordial follicles indicates the total number of primordial follicles per ovary. A similar method was used to count and calculate the total number of primary follicles. Follicles with more than one layer of granulosa cells were defined as secondary follicles. Only secondary follicles with non-atretic and healthy granulosa cells were counted for total number. Secondary follicles were counted only when they had nucleoli in oocyte nucleus to exclude the possibility of duplicate counting. The total number of those was parallel with the counted nucleoli because prominent nucleoli in those existed within a single $5 \mu \mathrm{m}$ section of tissue. The total number of those was not determined by dividing by the average number of sections in which they appeared because only secondary follicles with nucleoli were counted.

\section{TUNEL assay, IF and IHC}

Ovarian sections processed with the DeadEnd Fluorometric TUNEL System kit (G3250, Promega Co.) to detect and quantify apoptotic cells, per the manufacturers' protocol. Ovarian sections were used for TUNEL staining after fixing in formaldehyde. The detailed methods for IF and IHC have been described previously (Kim et al. 2013, 2015). MSY2 antibody (1: 2000) was a gift from Dr Schultz, RM, University of Pennsylvania. The DAB Peroxidase Substrate Kit (SK-4100, Vector Laboratories, Burlingame, CA, USA) was used for IHC. The TSA Plus Fluorescein System Kit (NEL741001KT, PerkinElmer, Inc.) was used for IF. The catalog numbers and sources of primary antibodies were as follows: Ki67 (ab833-500, 1:100) from Abcam; p-H3 (3377S, 1:50), $\gamma \mathrm{H} 2 \mathrm{AX}$ (9718s, 1:100), phospho-p63 (4981s, 1:50), cleaved PARP (9548s, 1;100), phospho-ATR (2853T, 1:50), phospho-CHK1 (12302T, 1:50), phosphoCHK2 (2197S, 1:50) and phospho-AKT (9271s, 1:50) from Cell Signaling; phospho-ATM (05-740, 1:50) from Millipore and Bax (P-19) (sc-526, 1:50) from Santa Cruz Biotechnology, Inc. For counting Ki67-positive cells, ovarian sections were used for IF assay with Ki67, and then $20 \times$ images were taken of each sample. Four nonoverlapping images were randomly taken per each ovarian section and used for counting all Ki67-positive cells.

\section{Anti-Mullerian hormone (AMH) assay}

Whole blood was collected from three strains of mice (CD-1, C57BL/6J and BALB/cJ) after 1, 3 and 7 days post injection of $150 \mathrm{mg} / \mathrm{kg}$ CPA at PD5. Additionally, it was taken from CD-1 after 14 days post injection of $150 \mathrm{mg} / \mathrm{kg}$ CPA at PD5. Terumo Capiject Capillary Blood Collection Tubes (T-MG, Terumo Medical Corporation, Tokyo, Japan) were used for separating the serum from whole blood. Mouse AMH ELISA Kit (MBS2507173, MyBioSource, Inc., San Diego, CA, USA) was used according to standard protocol for testing the AMH level of collected serum.

\section{Statistical analysis}

Data are presented as mean \pm S.D. For a comparison of means between more than two independent groups, 
one-way ANOVA (Adare et al. 2013) was performed, while the difference between two groups was analyzed by Tukey's range test with one-way ANOVA (and nonparametric) for statistical comparisons using PRISM 5.0 (GraphPad Software). Values of $P<0.05$ were considered to be statistically significant. ${ }^{*} P<0.05 ;{ }^{* *} P<0.01 ;{ }^{* \star *} P<0.001 ;$ n.s., non-significant.

\section{Results}

\section{CPA reduces the number of primordial follicles without increasing the number of early-stage growing follicles}

To investigate the effect of CPA on murine ovaries, $150 \mathrm{mg} / \mathrm{kg}$ CPA or PBS (vehicle control) was injected i.p. into three different strains of mice (CD-1, C57BL/6J and $\mathrm{BALB} / \mathrm{CJ}$ ) at 8 weeks of age (Fig. 1A). The mouse strains and the dose of CPA were selected based on those used in previous publications (Kalich-Philosoph et al. 2013, Roness et al. 2013, Goldman et al. 2017, Kano et al. 2017). After $24 \mathrm{~h}$, ovaries were harvested for histological analysis and follicle counting. No significant differences were noted in primordial follicle histology or numbers in CD-1 and BALB/CJ mice treated with PBS or CPA (Fig. 1B and $\mathrm{D}$ ), but $\mathrm{C} 57 \mathrm{BL} / 6 \mathrm{~J}$ mice did show a decrease in the primordial follicle number after CPA treatment (Fig. 1C). The primary follicle number was not increased in CPA-treated C57BL/6J mice, however (Fig. 1C) suggesting that the decrease in primordial follicles was not due to their activation and entry into the growing pool.

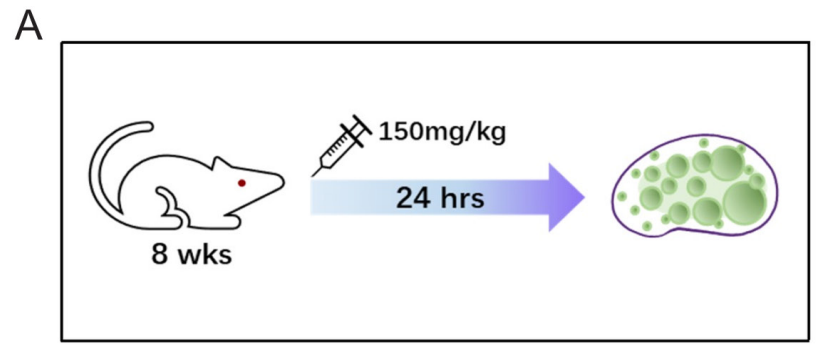

C

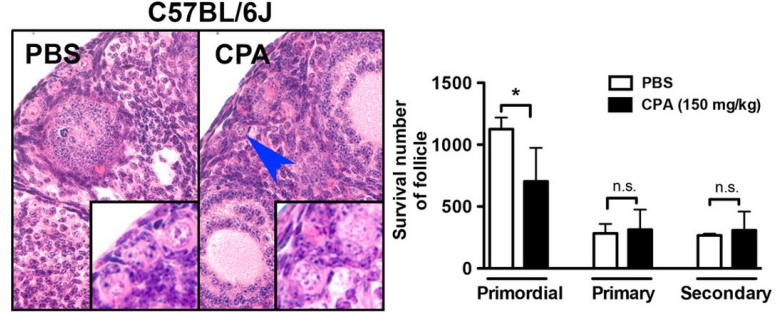

To determine whether CPA metabolites can elicit a prolonged effect on folliculogenesis in vivo, 7-week-old CD-1 mice were injected i.p. with either $200 \mathrm{mg} / \mathrm{kg}$ or $75 \mathrm{mg} / \mathrm{kg}$ CPA and ovaries were collected after 1 week (Fig. 2Ai). Although $80 \%$ of primordial follicles were depleted 1 week after injection of $200 \mathrm{mg} / \mathrm{kg}$ CPA, the number of primary follicles did not increase (Fig. 2Aii). The $75 \mathrm{mg} / \mathrm{kg}$ CPA dose did not have any effect on the number of primordial, primary or secondary follicles (Fig. 2Aiii). We also examined the effect of repeated exposure to CPA, injecting 4-week-old CD-1 mice with either $75 \mathrm{mg} / \mathrm{kg}$ or $150 \mathrm{mg} / \mathrm{kg}$ CPA once weekly for 4 weeks (Fig. 2Bi). Although the number of primordial follicles decreased with CPA treatment at either dose, again, there was no significant change in the number of primary or secondary follicles (Fig. 2B, ii and iii). Together, these data indicate that CPA and its metabolites specifically destroy primordial follicles without activating them. Of note, CPA treatment destroyed granulosa cells and cumulus cells in growing and antral follicles (Supplementary Fig. 1, see section on supplementary data given at the end of this article), but did not eliminate those follicles within the limited treatment time period.

\section{CPA induces death of primordial oocytes and granulosa cells of growing follicles}

To investigate the mechanism underlying the observed effect of CPA on follicles, a single dose of $150 \mathrm{mg} / \mathrm{kg} \mathrm{CPA}$ was injected i.p. into different strains of mice $(\mathrm{CD}-1$, $\mathrm{C} 57 \mathrm{BL} / 6 \mathrm{~J}$ and $\mathrm{BALB} / \mathrm{CJ}$ ) on PD5. Ovaries were harvested

$\mathrm{B}$
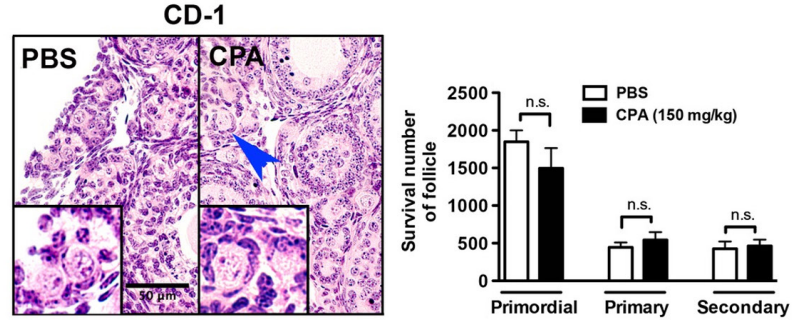

D
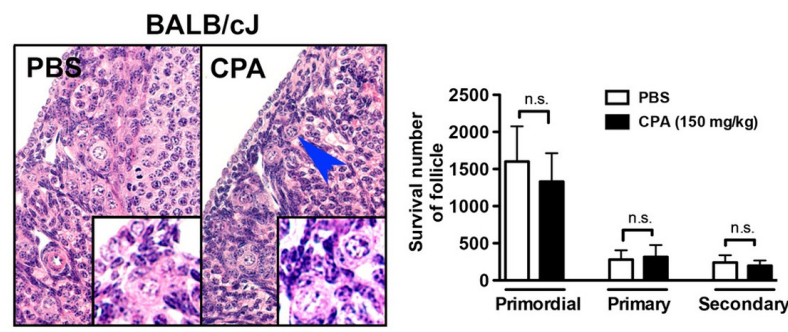

Figure 1

CPA does not increase the growing pool of follicles. (A) Three different strains of 8-week-old mice were injected with $150 \mathrm{mg} / \mathrm{kg}$ CPA for $24 \mathrm{~h}$ and the ovaries were fixed for H\&E staining and follicle counting. Representative images and surviving primordial, primary and secondary follicles are shown for CD-1 (B), C57BL/6J (C) and BALB/CJ (D) mice. 
A i)

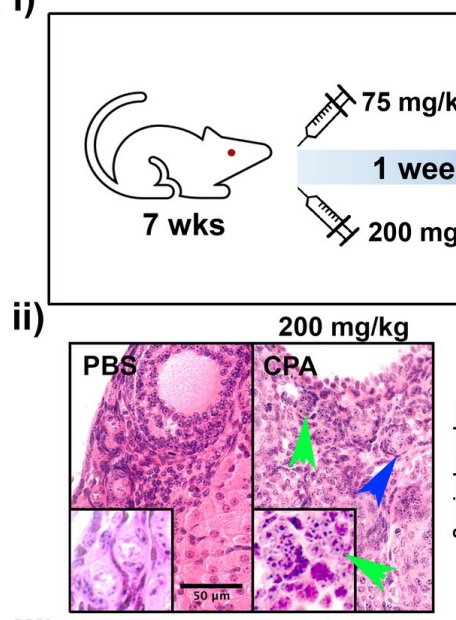

iii)

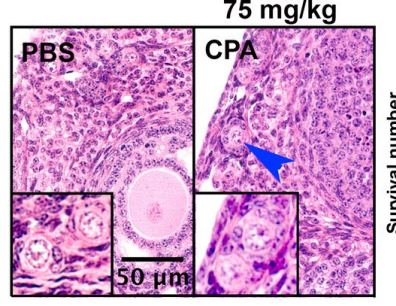

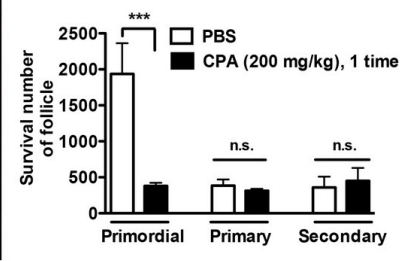

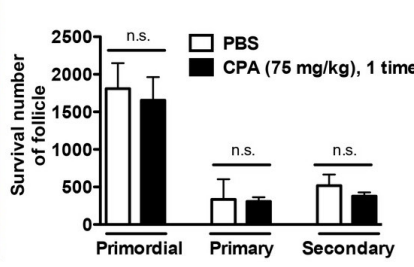

B i)

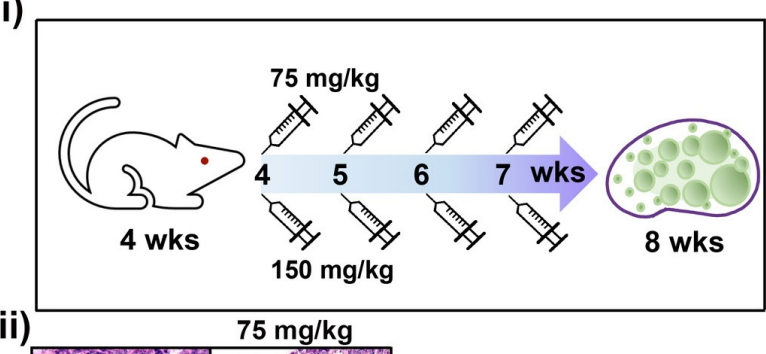

ii)
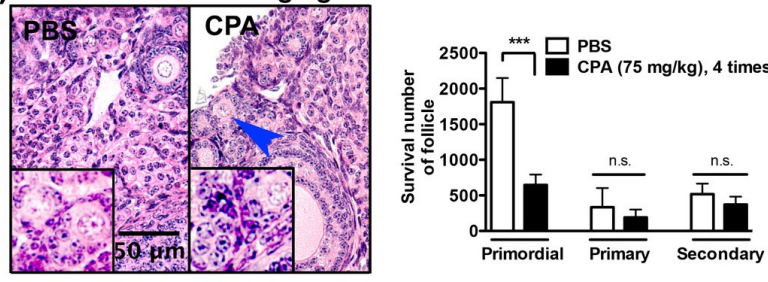

iii)
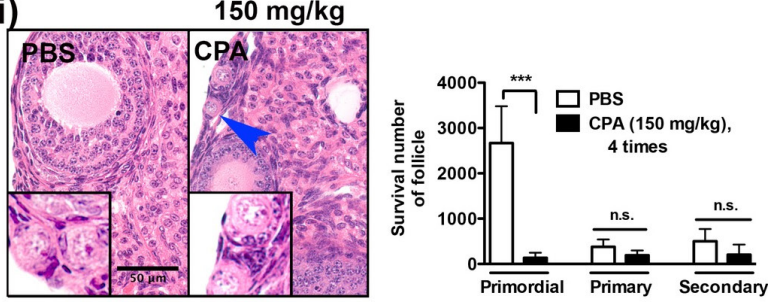

Figure 2

Gonadotoxicity of CPA in mice is dose and time dependent. (A) 7-week-old CD-1 mice were injected with CPA $200 \mathrm{mg} / \mathrm{kg}$ ( $n=3$ ) (i) or 75 mg/kg ( $n=3$ ) (ii) and ovaries were harvested 1 week post injection. (B) 4-week-old CD-1 mice were injected with CPA 75 mg/kg ( $n=3$ ) (i) or 150 mg/kg ( $n=3$ ) (ii) weekly for 4 weeks and ovaries were harvested 1 week after the last injection. Surviving primordial follicles are marked with a blue arrow. A follicle-like structure without a primordial oocyte following CPA treatment is marked with a green arrow. All experiments were performed in triplicate. Scale bar, $50 \mu \mathrm{m}$.

after 1, 3 and 7 days (Fig. 3A). All mice injected with CPA had smaller body sizes, lower body weights and less fur (Supplementary Fig. 2). Ovarian histology on day 1 after CPA injection revealed damaged primordial oocytes surrounded by healthy pre-granulosa cells and healthy primary and secondary oocytes surrounded by damaged granulosa cells (Fig. 3B). To quantify the effect of CPA on follicle development, each class of surviving follicles was counted in serial sections. Consistent with ovarian histology, CPA caused a significant decrease in the number of primordial follicles beginning at day 1 post injection in all three mouse strains (Fig. 4A). All the remaining primordial follicles on day 1 after CPA injection were lost by day 3 post injection in CD-1 and C57BL/6J mice. In BALB/cJ mice, CPA dramatically destroyed most of the primordial follicles by day 3 post injection (Fig. 4A). The number of primary follicles did not increase by 3 days after CPA injection, but instead decreased by 7 days post injection in all three strains compared to PBS-treated controls (Fig. 4A). The number of secondary follicles was significantly lower in the CPA group compared to the control group by 7 days post injection in CD-1 mice. Over the treatment period, the data demonstrate a gradual decrease in the number of primary follicles and increase in the number of secondary follicles in all three mouse strains (Fig. 4A). The ratio of growing follicles to dormant follicles increased at day 3 after CPA injection and showed a significant increase at day 7 post injection, reflecting a dramatic loss of dormant follicles (primordial follicles) with steadily increasing numbers of primary follicles and secondary follicles. Thus, we concluded that CPA destroys primordial follicles without increasing primary and secondary follicles (Fig. 4B).

To further evaluate the number of growing follicles, we also measured serum AMH levels from the three strains of PBS- and CPA-treated mice. The level of AMH in CPAtreated mice decrease by 3 days post injection in CD-1 and $\mathrm{BALB} / \mathrm{cJ}$ mice, while the level of AMH steadily increased in PBS-treated CD-1 and C57BL/6J mice and constantly remained in PBS-treated BALB/CJ mice by 7 days post injection. In addition, serum AMH levels were lower in the CPA-treated group compared to the control group at 3 and 7 days post injection (Fig. 4C), contrary to previous reports (Kalich-Philosoph et al. 2013), but consistent with our finding that CPA destroyed granulosa cells in growing and antral follicles (Supplementary Fig. 1). 

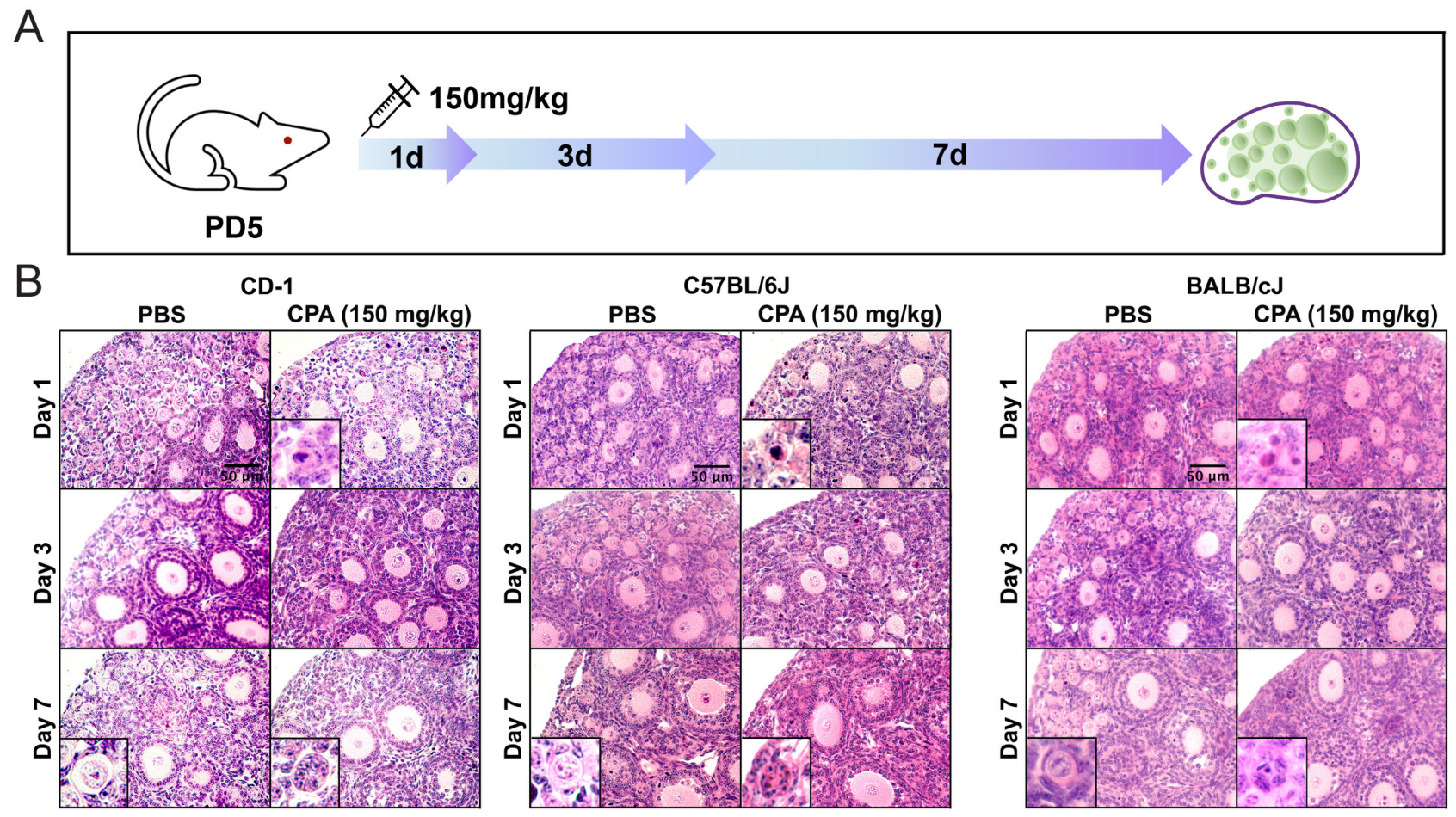

\section{Figure 3}

CPA destroys primordial follicles and primary follicles. (A) Three different strains of mice (CD-1, C57BL/6) and BALB/c) were injected at P5 with $150 \mathrm{mg} / \mathrm{kg}$ CPA and the ovaries were harvested at days 1, 3 and 7 post injection ( $n=3$ animals for each timepoint). (B) Representative images of H\&E staining of ovaries from each mouse strain at each time point. Scale bar, $50 \mu \mathrm{m}$.

Because the remaining healthy granulosa cells in secondary follicles would eventually proliferate and secrete $\mathrm{AMH}$ and the increase of secondary follicles by 7 days post injection, we observed the serum AMH levels in CPA-treated mice did not increase by day 7, especially in BALB/cJ (Fig. 4C).

\section{CPA induces the loss of primordial oocytes through apoptosis}

To test if CPA induces activation of primordial follicles by stimulating granulosa cell proliferation in primordial follicles, we performed IF assay of Ki67 on ovarian tissue sections from PD5 and 8-week-old CD-1 mice treated with $150 \mathrm{mg} / \mathrm{kg}$ CPA (Fig. 5A). The signals of Ki67 were mostly detected in granulosa cells of secondary follicles at PD5 mice and counted with four non-overlapped images from each sample. The number of Ki67-positive cells decreased by 3 days $(72 \mathrm{~h})$ after CPA treatment; this is in contrast to a previous report (Kalich-Philosoph et al. 2013). However, the numbers of Ki67-positive cells were comparable in PBS and CPA injected 8-week-old mice (Fig. 5A and Supplementary Fig. 3), implying that
CPA does not activate primordial follicles into growing pools of follicles.

To determine whether CPA induces apoptosis in primordial oocytes and granulosa cells of growing follicles, TUNEL assays were performed on ovaries from mice treated with CPA. On day 1 post-injection of CPA, ovaries showed extensive TUNEL-positive signals, which disappeared by 7 days after CPA injection (Fig. 5B). Although most of the primordial oocytes contained TUNEL-positive signals, the signals were not limited to primordial oocytes (Fig. 5Ca). TUNEL-positive signals were also observed in granulosa cells of primary and secondary follicles (Fig. 5C, b and c) and somatic cells of the stroma (Fig. 5Cd). TUNEL-positive signals were more extensive in granulosa cells of secondary follicles, implying there was more mitotic activity in granulosa cells of those (orange arrow, Fig. 5Cc).

Ovarian histology from day 1 post injection of $150 \mathrm{mg} / \mathrm{kg}$ CPA in CD-1 mice indicated that multilayer follicles had some pyknotic cells among the proliferating granulosa cells, but no damage to oocytes (red arrow, Fig. 5Di). Primordial oocytes were destroyed as a result of CPA treatment (yellow arrow, Fig. 5Dii), despite no damage in the pregranulosa cells surrounding the primordial 
A CD-1
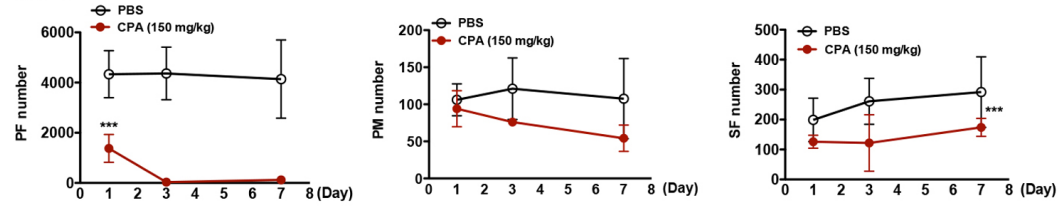

C57BL/6J
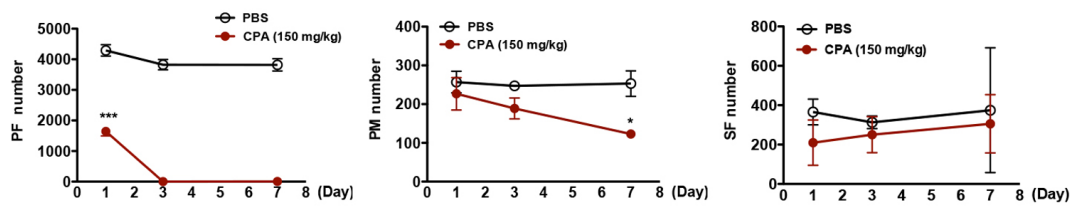

BALB/c J
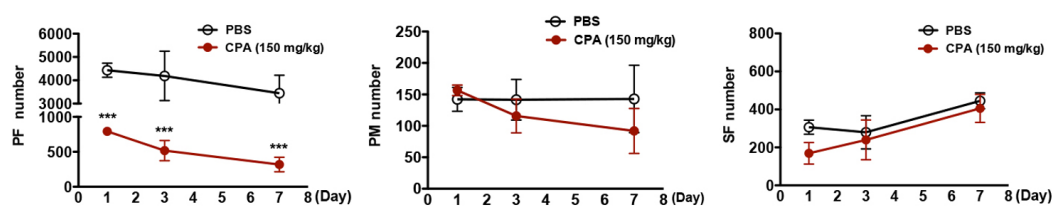

B

CD-1
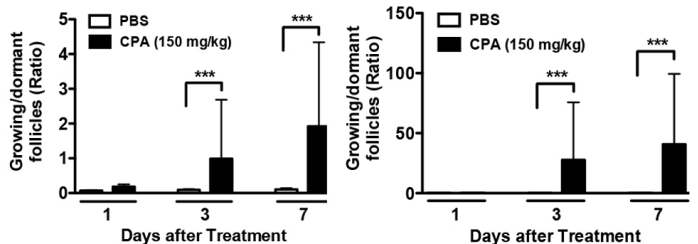

C

CD-1

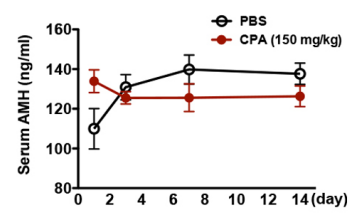

C57BL/6J

C57BL/6J

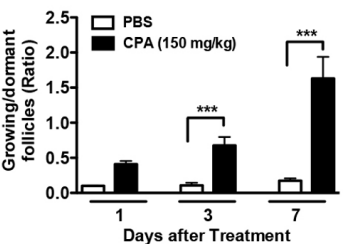

BALB/cJ

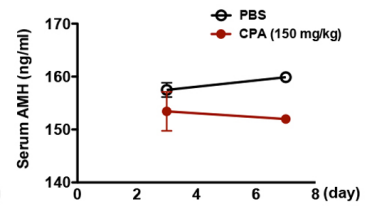

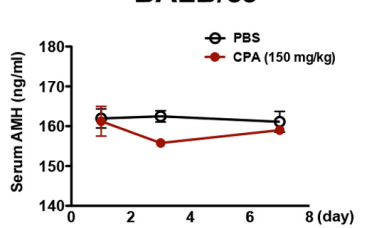

\section{Figure 4}

CPA induces loss of primordial follicles and primary follicles. (A) Total number of surviving primordial, primary and secondary follicles per ovary at 1, 3 and 7 days after CPA or PBS injection. Change in the number of each class of follicles over time after treatment of three different strains of PD5 mice with CPA or PBS. (B) Ratio of growing follicles to dormant follicles at 1, 3 and 7 days after treatment of three different strains of PD5 mice with CPA or PBS. (C) Level in serum AMH over time after treatment of three different strains of PD5 mice with CPA or PBS (all $n=4$ each). PF, primordial follicles; PM, primary follicles; SF, secondary follicles. oocytes (blue arrow, Fig. 5Dii). Interestingly, the somatic cells around primary follicles also appeared healthy after CPA exposure (blue arrow, Fig. 5Diii). By day 3 after CPA treatment, damaged granulosa cells were barely observed in multilayer follicles, which showed mitotic cells (orange arrow, Fig. 5Div). Most of the primordial follicles lost oocytes, leaving follicle-like structures at day 3 post injection later on under the epithelial cell layer (green arrow, Fig. 5Dv), implying that primordial oocytes are the most sensitive cells to CPA treatment. Healthy somatic cells filled the space (blue, Fig. 5Dvi).

As ovarian histology revealed the presence of healthy, proliferative granulosa cells in the ovaries of CPA-treated mice, a proliferation marker, phospho-H3 (p-H3) signals gradually increased in granulosa cells of secondary and multilayer follicles on day 3 and day 7 post injection of CPA (Fig. 5E).

\section{4-HC induces the loss of primordial oocytes through apoptosis in vitro}

To investigate whether metabolites of CPA directly affect and destroy primordial oocytes and granulosa cells in growing follicles, ovaries were isolated from PD5 CD-1 mice and cultured in vitro with 4-HC for $96 \mathrm{~h}$. Consistent with our in vivo results, ovarian histology revealed a dose-dependent effect of 4-HC on oocytes of primordial follicles (yellow arrow, Fig. 6A) and granulosa cells of primary follicles and secondary follicles (red arrow, Fig. 6A). Again, pregranulosa cells surrounding primordial oocytes appeared healthy at 4 -HC concentrations up to $1 \mu \mathrm{M}$, which destroyed all primordial oocytes and all granulosa cells of secondary follicles (Fig. 6A). However, stromal cells appeared unaffected at 4 -HC concentrations up to $1 \mu \mathrm{M}$, while those cells in the cortex were severely damaged at $10 \mu \mathrm{M}$. DAB staining 


\begin{tabular}{|l|l|l|r|r|}
\hline $\begin{array}{l}\text { Journal of } \\
\text { Endocrinology }\end{array}$ & Y Luan et al. & $\begin{array}{l}\text { Cyclophosphamide induces } \\
\text { apoptosis of primordial follicles }\end{array}$ & $\mathbf{2 4 0 : 2}$ & $\mathbf{2 5 0}$ \\
\hline
\end{tabular}

A

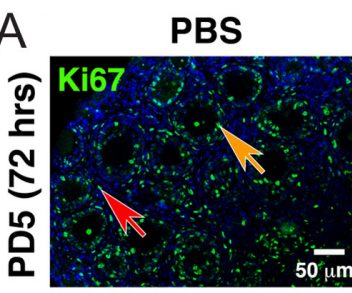

CPA (150 mg/kg)

B

PBS
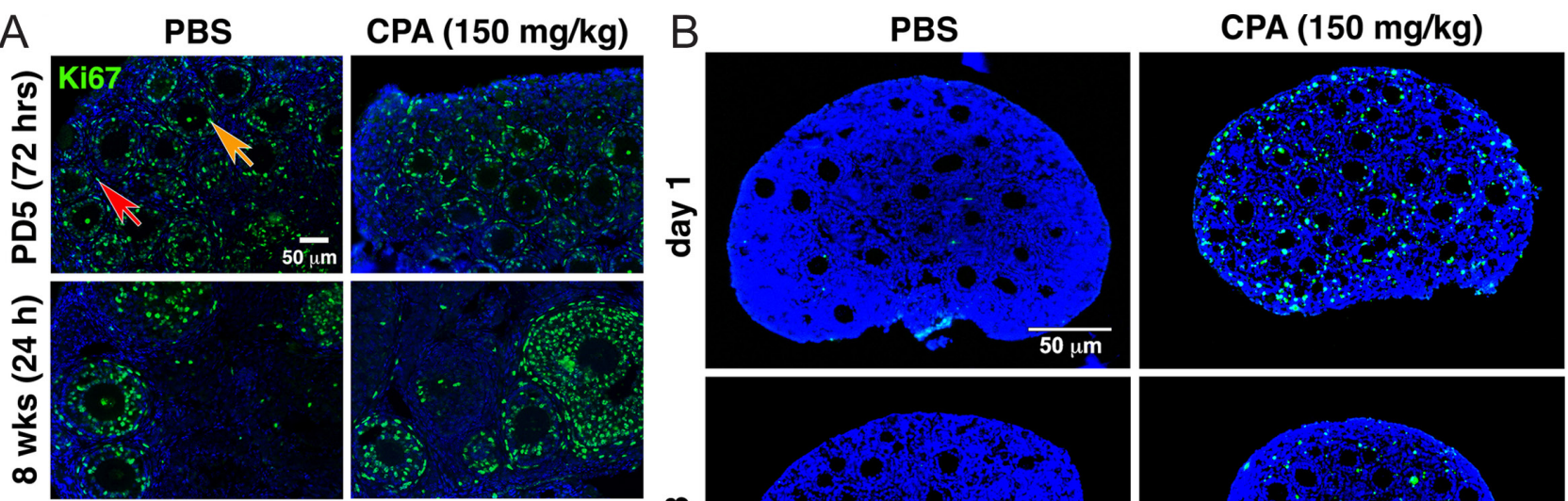

C

CPA (150 mg/kg)

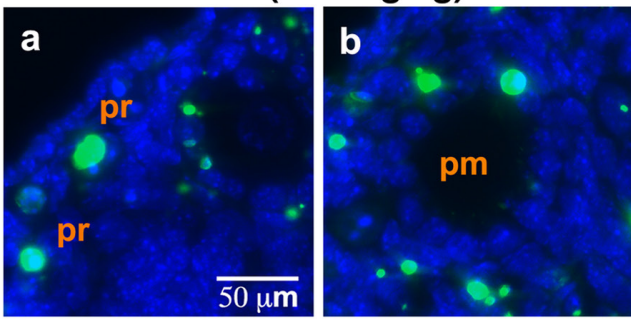

m
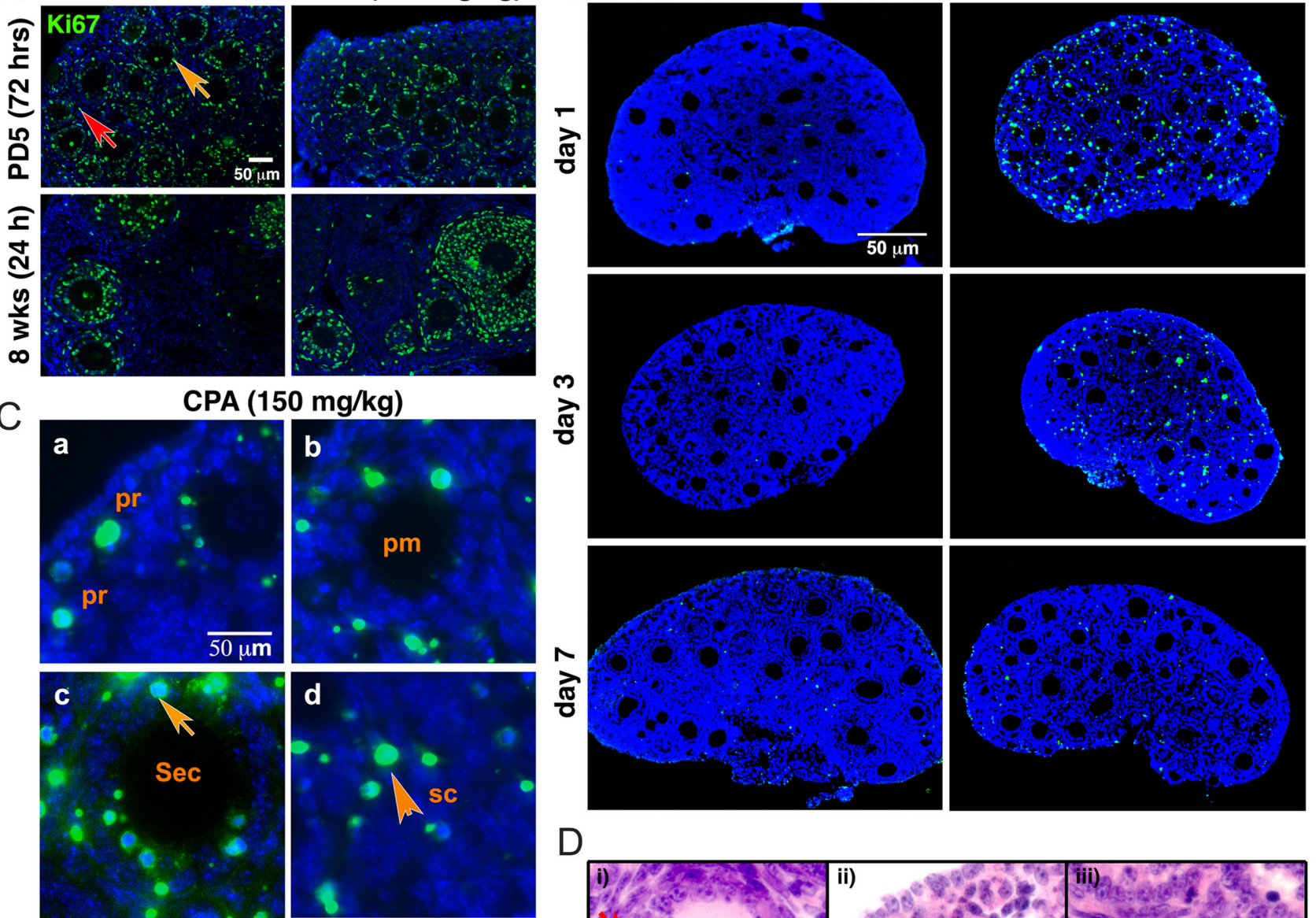

E

PBS

CPA $(150 \mathrm{mg} / \mathrm{kg})$

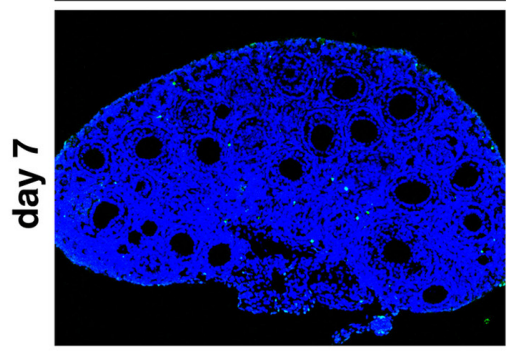

D

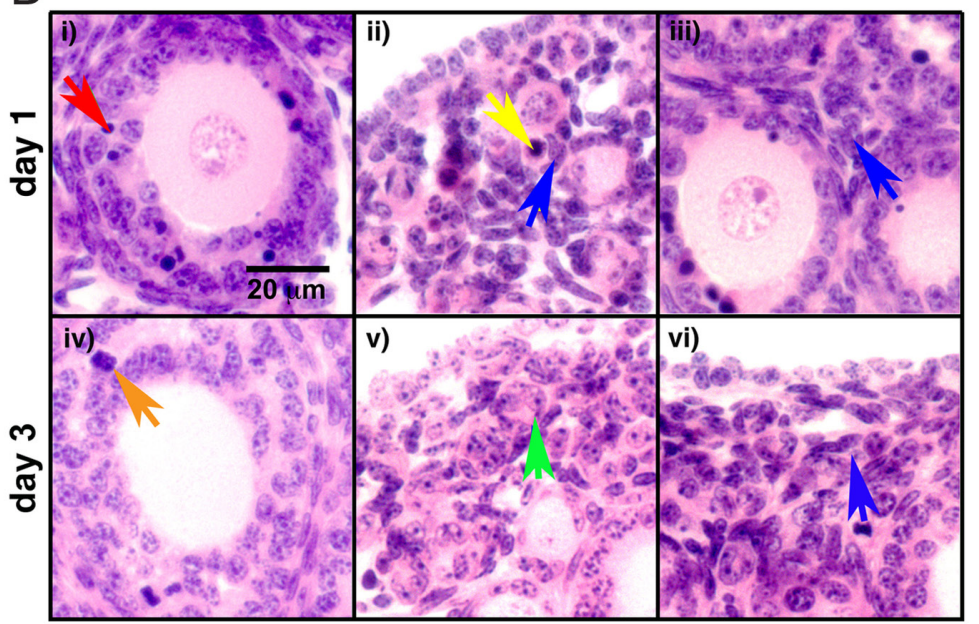

Figure 5

CPA induces cell death, not cell proliferation. (A) Representative images $(n=3)$ of Ki67 staining in PD5 $(72 \mathrm{~h})$ or 8-week-old mouse ovary 1 day $(24 \mathrm{~h})$ after injection of PBS or $150 \mathrm{mg} / \mathrm{kg}$ CPA. Granulosa (orange) and somatic cells (red) were marked with arrows. Green = Ki67, blue = DAPI. Scale bar, $50 \mu \mathrm{m}$. (B) Representative images of TUNEL staining of PD5 CD-1 mouse ovary 1, 3 and 7 days after injection of $150 \mathrm{mg} / \mathrm{kg}$ CPA or PBS. Green $=$ apoptotic cells, blue = DAPI. Scale bar, $50 \mu \mathrm{m}$. (C) High magnification representative images of TUNEL staining 1 day after injection of $150 \mathrm{mg} / \mathrm{kg}$ CPA, showing positive TUNEL signals (green) in a primordial follicle ( $p r, a)$, primary follicle (pm, b), secondary follicle (sec, c) and somatic cell (sc, d). Blue=DAPI. Granulosa cells of secondary (sec) follicles and somatic cells (sc) are indicated with orange arrows. Scale bar, $50 \mu \mathrm{m}$. (D) Representative H\&E images of PD5 CD-1 mouse ovary 1 and 3 days after injection of CPA. Dead granulosa cells (red arrow, i), dead primordial oocyte (yellow arrow, ii), healthy pregranulosa cells (blue arrow, ii), healthy stromal cells (blue arrow, iii), proliferating granulosa cells (orange arrow, iv), follicle-like structure without oocyte (green arrow, v) and healthy somatic cells (blue arrow, vi) are marked in each panel. Scale bar, $20 \mu \mathrm{m}$. (E) Representative images of p-H3 staining in PD5 mouse ovaries 3 and 7 days after injection of $150 \mathrm{mg} / \mathrm{kg}$ CPA or PBS. Green = p-H3, blue = DAPI. Scale bar, $200 \mu \mathrm{m}$. 


\begin{tabular}{l|l|l|r|r|}
$\begin{array}{l}\text { Journal of } \\
\text { Endocrinology }\end{array}$ & Y Luan et al. & $\begin{array}{l}\text { Cyclophosphamide induces } \\
\text { apoptosis of primordial follicles }\end{array}$ & $\mathbf{2 4 0 : 2}$ & 251 \\
\hline
\end{tabular}

A

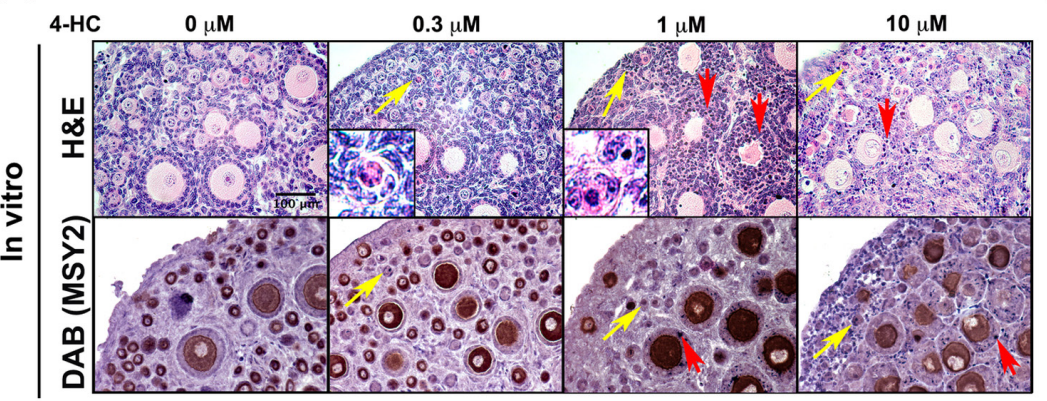

B

$\mathrm{C}$

$1 \mu \mathrm{M}$ 4-HC

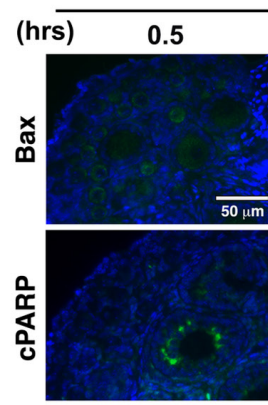

3
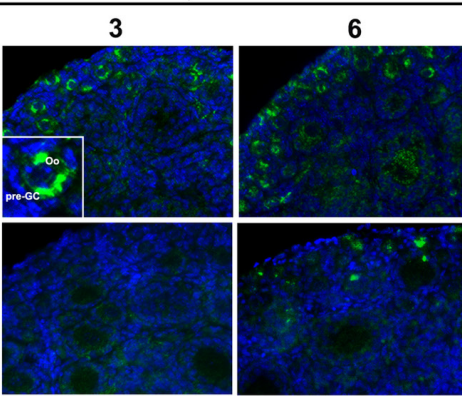

$1 \mu \mathrm{M}$ 4-HC

D
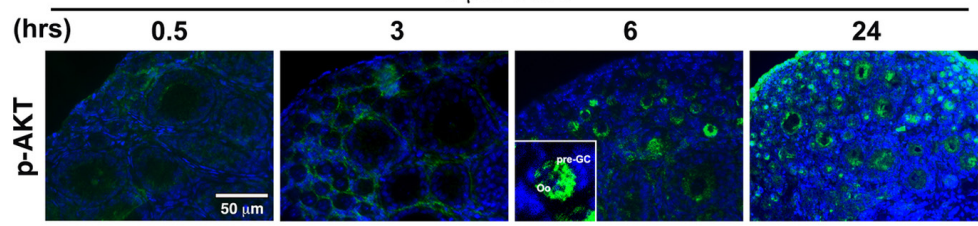

E

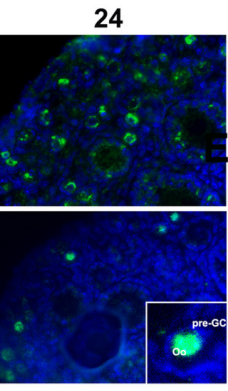

E
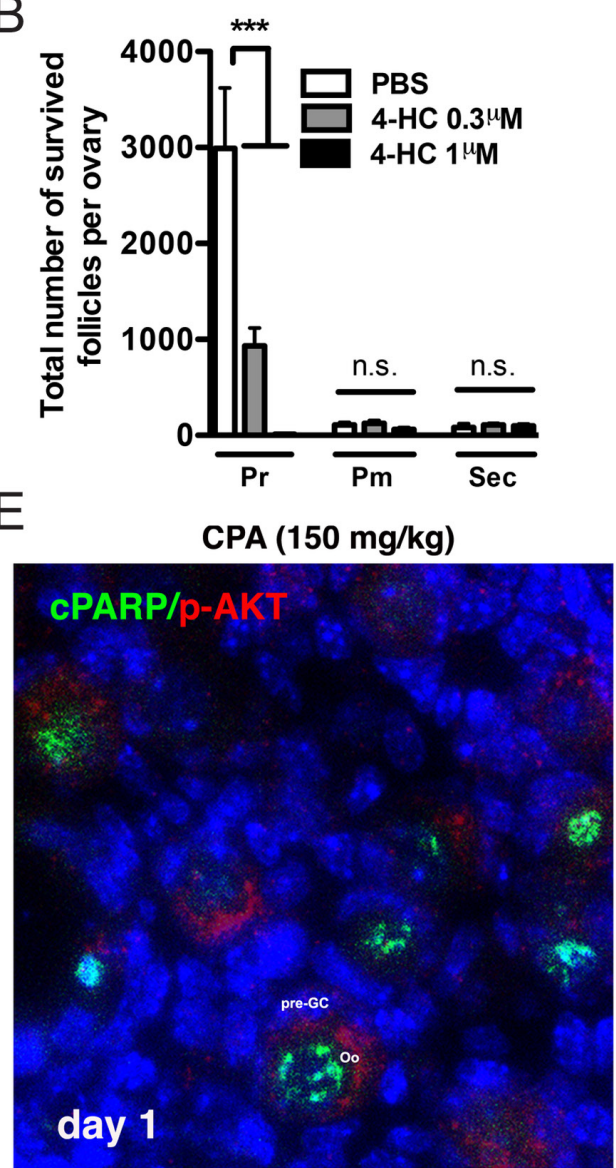

Figure 6

4-HC destroys primordial follicles through activation of apoptosis. (A) Representative images of H\&E and IHC of MSY2 $(n=3)(D A B)$ indicating damaged primordial oocytes (yellow arrows) and granulosa cells and somatic cells (red arrows). Scale bar, $100 \mu \mathrm{m}$. (B) The number of surviving primordial follicles significantly decreased after culturing ovaries in vitro with 4-HC compared with PBS ( $n=5$ each). ***, $P<0.001$; n.s, non-significant. (C) Representative images of the time-dependent expression of BAX and CPARP in ovarian tissue cultured with $1 \mu \mathrm{M} 4-\mathrm{HC}$. Green = BAX or CPARP, Blue = DAPI. Scale bar, $50 \mu \mathrm{m}$. (D) Representative images showing time-dependent expression of p-AKT in ovarian tissues cultured with $1 \mu \mathrm{M} 4-\mathrm{HC}$. Green $=\mathrm{p}-\mathrm{AKT}$, Blue $=\mathrm{DAPI}$. Scale bar, $50 \mu \mathrm{m}$. (E) Representative image showing co-expression of CPARP and p-AKT in PD5 ovaries 1 day after injection of $150 \mathrm{mg} / \mathrm{kg}$ CPA.

Green $=$ cPARP, Red $=$ p-AKT, Blue $=$ DAPI.

with MSY2, an oocyte cytoplasm-specific marker and RNAbinding protein, indicated a dose-dependent decrease in the number of small oocytes in the cortex (Fig. 6A). Treatment of the ovary with 4-HC led to a significant decrease in the number of primordial follicles (Fig. 6B).

To understand the mechanism of primordial follicle loss induced by $4-\mathrm{HC}$, the levels of apoptotic markers BAX and CPARP and the activation marker p-AKT were examined in ovaries treated with $1 \mu \mathrm{M} 4$-HC for increasing lengths of time. BAX in oocyte cytoplasm and cPARP in oocyte nuclei were increased by $4-\mathrm{HC}$ in primordial oocytes at 3 and $6 \mathrm{~h}$, respectively (Fig. 6C). Unexpectedly, the p-AKT signal in oocytes was also induced at $6 \mathrm{~h}$ and was significantly increased at $24 \mathrm{~h}$ (Fig. 6D). The expression of p-AKT in PD5 mouse ovary is usually limited to stromal cells and undetectable in primordial follicles; however, treatment with 4-HC induced the expression of p-AKT in oocytes. To examine the expression of apoptotic and activation markers at the same time, co-staining of cPARP and p-AKT was performed in ovarian sections of in vivo CPA-treated mice. One day after CPA injection, the ovaries showed co-expression of cPARP and p-AKT in primordial oocytes (Fig. 6E). However, this signal was not seen 3 days after CPA injection, suggesting that primordial oocytes are most likely activated and then undergo apoptosis.

\section{Inhibitors of apoptotic pathway components protect follicles from CPA-induced damage}

IF revealed that primordial oocytes express $\gamma \mathrm{H} 2 \mathrm{AX}$ and p-p63 after injection of mice with $150 \mathrm{mg} / \mathrm{kg}$ CPA (Fig. 7A). IF also showed the presence of the apoptosis-related proteins 
p-ATR, p-CHK1 and p-CHK2 in primordial oocytes at $24 \mathrm{~h}$ after 4-HC treatment. While p-ATM was not activated by 4-HC treatment, p-CHK2, a downstream target of p-ATM, was detected (Fig. 7B). Thus, the p-ATR $>$ p-CHK1/Chk2>p-p63 apoptotic pathway was dominant after 4-HC treatment, rather than the p-ATM>p-CHK2 pathway. ETP46464, a highly specific ATR inhibitor, effectively protected primordial follicles from 4-HC-induced loss, but did not protect granulosa cells of multilayer secondary follicles from 4-HC-induced damage. In addition, CHK2 inhibitors (CK2II) effectively protected primordial follicles, but not granulosa cells of multilayer secondary follicles from 4-HC-induced damage (Fig. 7C and D). p-p63 $\alpha$ signals induced by 4-HC were barely detectable in primordial oocytes pretreated with either CK2II or ETP46464 (Fig. 7E). Thus, 4-HC destroys primordial oocytes through the $\mathrm{p}-\mathrm{ATR}>\mathrm{p}-\mathrm{CHK} 1 / \mathrm{p}-\mathrm{CHK} 2>$ p-p63>cPARP apoptosis pathway (Fig. 8).

\section{Discussion}

Previous reports suggest that primordial follicles in mice are directly or indirectly activated through $\mathrm{PI} 3 \mathrm{~K}>\mathrm{AKT}>\mathrm{mTOR}$ signaling pathways in response to CPA (Kalich-Philosoph et al. 2013, Roness et al. 2013). It has been hypothesized that primordial follicles initiate growth when secondary follicles are targeted and depleted by CPA. Here, we demonstrated that CPA specifically destroys dormant primordial follicles by directly inducing apoptotic cell death in primordial oocytes, rather than destroying growing follicles and indirectly depleting the primordial follicle pool through activation.

The existing literature on the effect of CPA on the ovary includes data from three independent murine strains (CD-1, C57BL/6J, and BALB/cJ) at different ages and treated with various concentrations of CPA $(75,150$ and
A

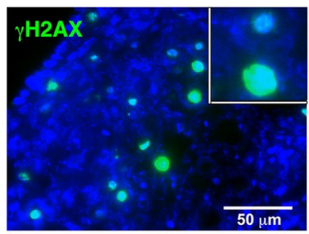

B

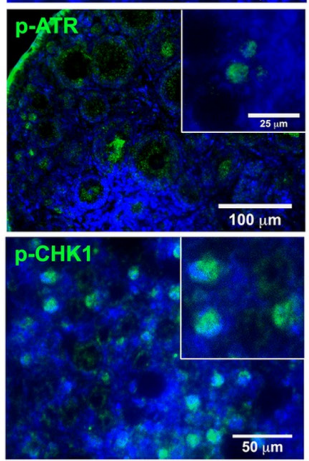

D

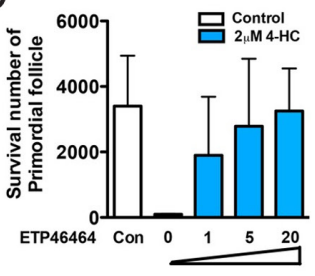

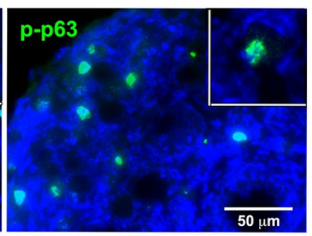
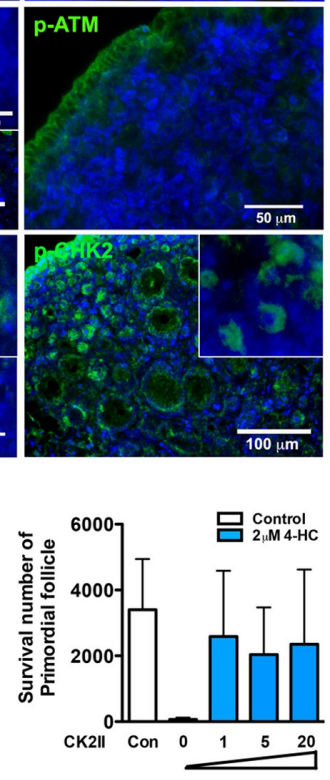

C

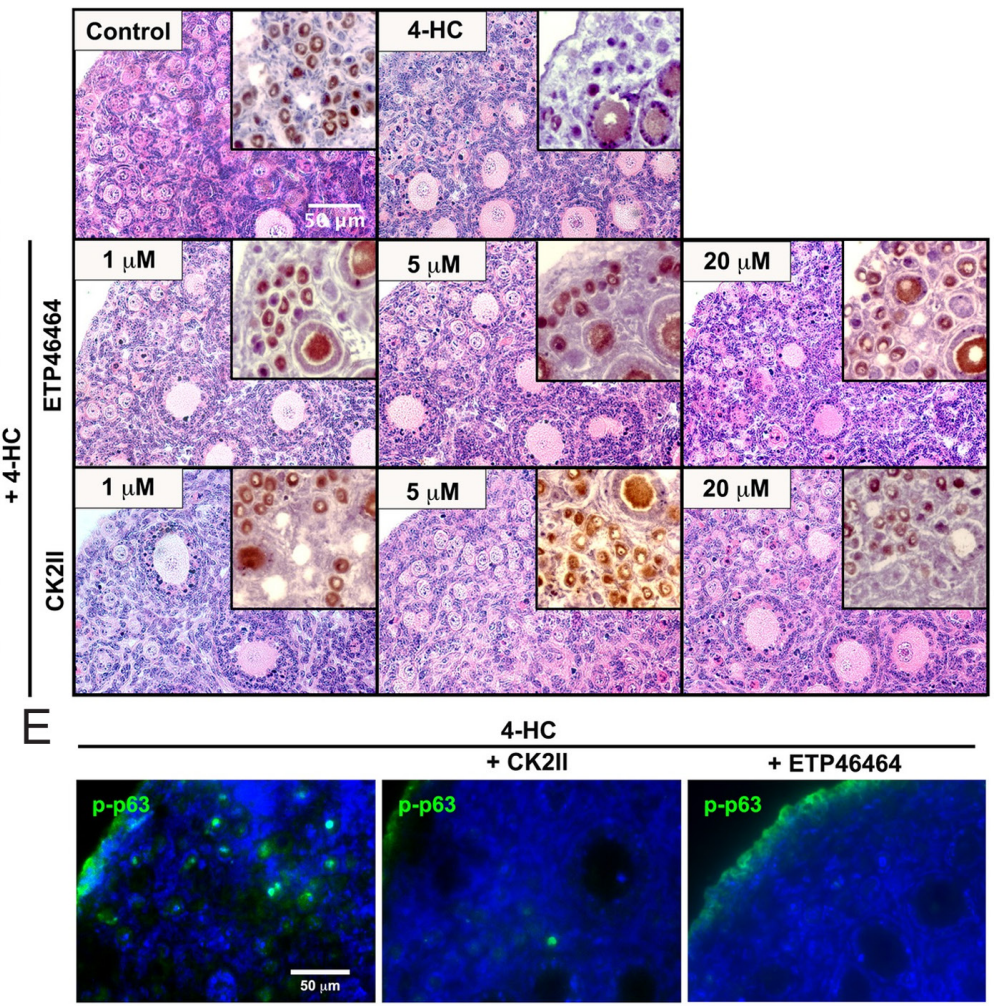

Figure 7

Apoptosis inhibitors protect the ovarian reserve from 4-HC-induced follicle damage in vitro. (A) Representative images of $\gamma \mathrm{H} 2 \mathrm{AX}$ and $\mathrm{p}$-p63 immunofluorescence (green) in ovaries of a PD5 CD-1 mouse 3 days after injection of $150 \mathrm{mg} / \mathrm{kg}$ CPA ( $n=4)$. Each inset shows a surviving primordial oocyte positive for each signal in the panel. Blue = DAPI. Scale bar, $50 \mu \mathrm{m}$. (B) Representative images of p-ATR, p-ATM, p-CHK1 and p-CHK2 immunofluorescence (green) in PD5 CD-1 mouse ovaries after treatment with $3 \mu \mathrm{M} 4-\mathrm{HC}$ for $24 \mathrm{~h}$ in vitro. Each inset shows primordial oocytes positive for each signal in the panel. Blue = DAPI. Scale bar, $100 \mu \mathrm{m}$ or $50 \mu \mathrm{m}$. (C) Representative images of H\&E and DAB staining for MSY2 in PD5 CD-1 mouse ovaries cultured in vitro with the indicated doses of each inhibitor (CK2II or ETP46464) and PBS (control) or $3 \mu \mathrm{M} 4-\mathrm{HC}$. Scale bar, $50 \mu \mathrm{m}$. (D) Number of surviving primordial follicles after culturing ovaries in vitro with each inhibitor and $2 \mu \mathrm{M} 4$ - HC. Experiments were performed in triplicate. (E) Representative images of p-p63 immunofluorescence (green) in PD5 CD-1 mouse ovaries treated with each inhibitor and $3 \mu \mathrm{M} 4-\mathrm{HC}$ for $24 \mathrm{~h}$ in vitro. Blue=DAPI. Scale bar, $50 \mu \mathrm{m}$. 


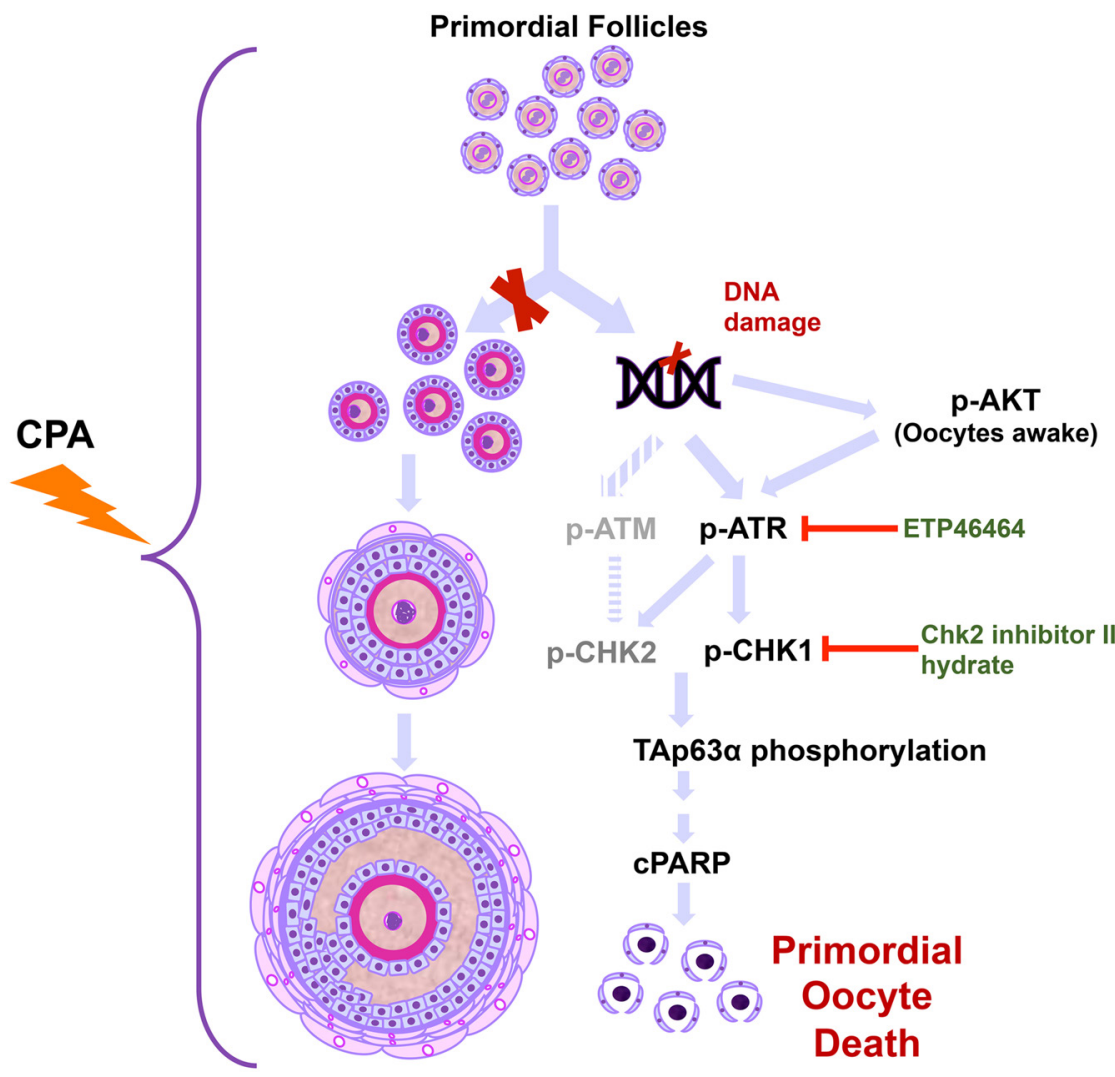

\section{Figure 8}

Schematic of the oocyte apoptotic pathway induced by CPA. The previously proposed hypothesis and newly tested hypothesis are shown. Based on our findings, CPA exposure induces apoptosis of primordial follicles, leading to oocyte death and depletion of the ovarian reserve. We did not observe activation of primordial follicles leading to an increase in the number of primary or secondary follicles.
$200 \mathrm{mg} / \mathrm{kg}$ ). We evaluated these same three strains, at four ages, and treated with various CPA doses, and consistently found that the loss of the ovarian reserve occurs by direct damage of primordial follicles by CPA in vivo. Of note, our experiments were performed with CPA doses that are clinically relevant $(150 \mathrm{mg} / \mathrm{kg}$ CPA administered every 7-10 days) (Peng et al. 2013). We showed a similar effect of 4-HC on primordial follicle destruction in vitro. We verified that CPA directly destroys granulosa cells from growing follicles including multilayer follicles, but does not destroy these follicles. None of the conditions tested showed evidence of an increase in the number of primary follicle and secondary follicles that would indicate overactivation of the primordial follicle pool by CPA. Instead, we documented an increase in the ratio of growing to dormant (primordial) follicles resulting from a dramatic loss of dormant follicles while the number of growing follicles remains the same.

A prior study suggested that AMH levels drop within $12 \mathrm{~h}$ of CPA treatment, then subsequently increase to twice baseline and are maintained for 14 days post-CPA treatment (Roness et al. 2013). The authors proposed that the increase in AMH levels was due to an increase in the number of early-stage growing follicles due to overactivation of dormant primordial follicles. However, we demonstrated that AMH serum levels fell within 3 days after CPA treatment, and then steadily increased to levels equivalent to those of PBS-treated mice by 7 days after CPA treatment. In addition, we found that granulosa cells damaged by CPA were replaced with healthy granulosa cells without activation of dormant primordial follicles, accounting for the rebound in AMH secretion over time. This was supported by histological analyses showing healthy granulosa cells in ovaries 3 days post CPA treatment (Fig. 3Aiv). In addition, TUNEL assays suggested that CPA directly targets primordial oocytes along with many different types of cells in the ovary. Ki67 staining results also conflicted with those of a previous report (Kalich-Philosoph et al. 2013). In PD5 CPA-treated mice, the Ki67 signal decreased 1 day post injection, suggesting that CPA does not stimulate granulosa cell proliferation. During this time, no cohort of primordial follicles is activated to increase the pool of growing follicles. Another report showed that low-dose CPA treatment of 60-day-old Sprague-Dawley rats for 4 weeks increased the number of growing follicles compared to an untreated control group (Letterie 2004). However, in our study, the number of primordial follicles decreased after injection of low-dose CPA $(75 \mathrm{mg} / \mathrm{kg}$ or $150 \mathrm{mg} / \mathrm{kg})$ once a week for 4 weeks, without an increase in the number of growing follicles. 
Apoptotic pathways in granulosa cells or oocytes, or indirect damage to ovarian stromal components, are commonly suggested mechanisms underlying chemotherapy-induced follicle death. A previous pioneering study showed that female germ cells are lost through apoptosis-associated signaling pathways when subjected to chemotherapy (Perez et al. 1997, 1999, Bergeron et al. 1998). Sphingosine-1-phosphate prevents oocytes death resulting from apoptosis-associated signaling pathways induced by doxorubicin (DXR) and radiation therapy (Morita et al. 2000, Paris et al. 2002). Stromal damage has been shown in human ovarian tissues after exposure to chemotherapies such as CDDP, doxorubicin and CPA (Marcello et al. 1990, Gonfloni et al. 2009). This damage is characterized by vascular infarcts and subcapsular focal cortical fibrosis, which only partly explain the diffuse and widespread follicle destruction (Kalich-Philosoph et al. 2013). Due to the broad use of CPA, it is important to know how CPA induces oocyte/granulosa cell death. It is known that the ovotoxic CPA metabolite PM destroys preferentially dividing cells, such as granulosa cells, in growing follicles, as shown by a decrease in the number of growing follicles compared to primordial follicles (Madden et al. 2014). In other reports, the ovotoxicity of CPA metabolites (PM and 4-HC) was related to a decrease in the number of primordial follicles and primary follicles after treatment (Desmeules \& Devine 2006).

Previous studies have proposed that CPA treatment stimulates the PI3K>AKT>mTOR pathway (KalichPhilosoph et al. 2013, Goldman et al. 2017); however, our IF assay results show that while p-AKT is rapidly expressed in primordial oocytes after exposure to CPA, it is co-expressed with cPARP. This suggests that follicles containing both signals are destined to die rather than activate. On the other hand, if follicles do not reach the threshold of death as a result of DNA damage, those with p-AKT may survive after DNA repair. However, our results revealed that most of the follicles with both p-AKT and cPARP signals die, as shown by the decrease in the number of primordial follicles on day 3 after injection of CPA. This suggests that dormant follicles are not activated and then 'burn out' through a CPA-stimulated PI3K>PTEN $>$ AKT pathway. Instead, we propose that treatment with continuous lowdose CPA induces apoptosis in dormant follicles due to an accumulation of DNA damage that surpasses the threshold of DNA repair. Other studies support this model of direct apoptosis in primordial follicles after treatment with chemotherapeutic agents (Phan et al. 1994, Soleimani et al. 2011). However, we do not exclude the possibility of consequences of AKT signals in primordial oocytes even after using inhibitors that block apoptotic markers, including p-ATR and p-CHK1/2. If AKT signals are upstream of p-ATR and p-CHK1, and are effective in activating oocytes, and if inhibitors to p-ATR and p-CHK1 do not suppress AKT signals within primordial oocytes, they could wake dormant primordial oocytes giving them time to repair DNA damage, and ultimately resulting in a greater number of activated follicles. However, this longterm process needs further investigation to be confirmed.

Understanding the exact mechanism of primordial follicle loss may reveal potential targets for development of adjuvant therapies to protect the ovarian reserve from gonadotoxic chemotherapeutic agents. Previous studies that proposed the 'activation-burn out' hypothesis of primordial follicle depletion in CPA-treated mice suggested that inhibitors of the PI3K>PTEN>AKT pathway would protect the ovarian reserve from CPA (Kalich-Philosoph et al. 2013, Goldman et al. 2017). However, based on our results, we propose that apoptosis pathway inhibitors may be candidate gonadoprotective agents against the toxic effects of CPA. We showed that two inhibitors, ETP-46464, a highly potent ATR-specific inhibitor (Forero et al. 2014, Beumer et al. 2015), and CHK2 inhibitors (CK2II), a Checkpoint 2 inhibitor (Coutandin et al. 2016, Rinaldi et al. 2017, Tuppi et al. 2018), efficiently protected primordial follicles from 4-HC-induced damage in ovary organ culture in vitro. These findings further support a model in which CPA destroys primordial follicles through apoptotic pathways, and provides a rationale for further study of these agents in vivo.

Understanding how independent chemotherapies affect gonadal function permits better understanding of the mechanisms protecting germ line integrity and provide insights into drug targets to protect primordial follicles following cancer treatments. This study found that CPA-induced damage of primordial follicles occurs via the p-ATR $>$ p-CHK1/p-CHK2>p-p63 apoptotic pathway. As shown previously, primordial follicles are highly sensitive to another alkylating agent, CDDP, and quickly die through apoptotic pathways via the TAp63 $\alpha>$ PUMA $>$ NOXA pathway (Gonfloni et al. 2009, Kerr et al. 2012a, Kim et al. 2013). Primordial follicles in Trp63-null mice showed resistance to CDDP, implying the importance of TAp63 $\alpha$ in primordial oocyte death. Recently, Tuppi et al suggested that doxorubicin and CDDP induce the tetramerization of TAp63 $\alpha$ by CHEK2-CK1 kinase (Tuppi et al. 2018). Our findings provide a rationale for further research into a feasible pharmacological intervention for protecting the ovarian reserve from the commonly used chemotherapeutic agent CPA. 


\section{Supplementary data}

This is linked to the online version of the paper at https://doi.org/10.1530/ JOE-18-0370.

\section{Declaration of interest}

The authors declare that there is no conflict of interest that could be perceived as prejudicing the impartiality of the research reported.

\section{Funding}

This work was supported by the Center for Reproductive Health After Disease (P5OHD076188) from the National Institutes of Health National Center for Translational Research in Reproduction and Infertility (NCTRI).

\section{Author contribution statement}

$Y L$ and $S Y K$ designed the study, performed the experiments, collected and analyzed data and wrote the manuscript; T K W provided conceptual advice; Y L, M E E, S Y K and T K W edited the manuscript.

\section{Acknowledgements}

The authors would like to thank Dr Schultz at the University of Pennsylvania for the generous gift of the MSY2 antibody. They would also like to thank Jing Xu (Oregon National Primate Research Center), Sharon Tam, Minju Lee and Dr Stacey Tobin (The Tobin Touch, Inc.) and Maxwell E Edmonds for editing this manuscript. This work was done at Northwestern University.

\section{References}

Adare A, Afanasiev S, Aidala C, Ajitanand NN, Akiba Y, Akimoto R, Al-Bataineh H, Al-Ta'ani H, Alexander J, Angerami A, et al. 2013 Medium modification of jet fragmentation in $\mathrm{Au}+\mathrm{Au}$ collisions at radical[s(NN)]=200 GeV measured in direct photon-hadron correlations. Physical Review Letters 111 032301. (https://doi. org/10.1103/PhysRevLett.111.032301)

Bergeron L, Perez GI, Macdonald G, Shi L, Sun Y, Jurisicova A, Varmuza S, Latham KE, Flaws JA, Salter JC, et al. 1998 Defects in regulation of apoptosis in caspase-2-deficient mice. Genes and Development $\mathbf{1 2}$ 1304-1314. (https://doi.org/10.1101/gad.12.9.1304)

Beumer JH, Fu KY, Anyang BN, Siegfried JM \& Bakkenist CJ 2015 Functional analyses of ATM, ATR and Fanconi anemia proteins in lung carcinoma : ATM, ATR and FA in lung carcinoma. BMC Cancer 15 649. (https://doi.org/10.1186/s12885-015-1649-3)

Bolcun-Filas E, Rinaldi VD, White ME \& Schimenti JC 2014 Reversal of female infertility by Chk2 ablation reveals the oocyte DNA damage checkpoint pathway. Science 343 533-536. (https://doi.org/10.1126/ science.1247671)

Chemaitilly W, Mertens AC, Mitby P, Whitton J, Stovall M, Yasui Y, Robison LL \& Sklar CA 2006 Acute ovarian failure in the childhood cancer survivor study. Journal of Clinical Endocrinology and Metabolism 91 1723-1728. (https://doi.org/10.1210/jc.2006-0020)

Coutandin D, Osterburg C, Srivastav RK, Sumyk M, Kehrloesser S, Gebel J, Tuppi M, Hannewald J, Schafer B, Salah E, et al. 2016 Quality control in oocytes by $\mathrm{p} 63$ is based on a spring-loaded activation mechanism on the molecular and cellular level. eLife 5 e13909. (https://doi. org/10.7554/eLife.13909)
Demeestere I, Basso O, Moffa F, Peccatori F, Poirot C \& Shalom-Paz E 2012 Fertility preservation in female cancer patients. Obstetrics and Gynecology International 2012 695041. (https://doi.org/10.1155/2012/695041)

Desmeules P \& Devine PJ 2006 Characterizing the ovotoxicity of cyclophosphamide metabolites on cultured mouse ovaries. Toxicological Sciences 90 500-509. (https://doi.org/10.1093/toxsci/kfj086)

Forero A, Giacobbi NS, McCormick KD, Gjoerup OV, Bakkenist CJ, Pipas JM \& Sarkar SN 2014 Simian virus 40 large T antigen induces IFN-stimulated genes through ATR kinase. Journal of Immunology 192 5933-5942. (https://doi.org/10.4049/jimmunol.1303470)

Fraiser LH, Kanekal S \& Kehrer JP 1991 Cyclophosphamide toxicity. Characterising and avoiding the problem. Drugs 42 781-795. (https:// doi.org/10.2165/00003495-199142050-00005)

Ganesan S \& Keating AF 2015 Phosphoramide mustard exposure induces DNA adduct formation and the DNA damage repair response in rat ovarian granulosa cells. Toxicology and Applied Pharmacology $\mathbf{2 8 2}$ 252-258. (https://doi.org/10.1016/j.taap.2014.11.017)

Goldman KN, Chenette D, Arju R, Duncan FE, Keefe DL, Grifo JA \& Schneider RJ 2017 mTORC1/2 inhibition preserves ovarian function and fertility during genotoxic chemotherapy. PNAS 114 3186-3191. (https://doi.org/10.1073/pnas.1617233114)

Gonfloni S, Di Tella L, Caldarola S, Cannata SM, Klinger FG, Di Bartolomeo C, Mattei M, Candi E, De Felici M, Melino G, et al. 2009 Inhibition of the c-Abl-TAp63 pathway protects mouse oocytes from chemotherapy-induced death. Nature Medicine 15 1179-1185. (https://doi.org/10.1038/nm.2033)

Hudson MM 2010 Reproductive outcomes for survivors of childhood cancer. Obstetrics and Gynecology 116 1171-1183. (https://doi. org/10.1097/AOG.0b013e3181f87c4b)

Kalich-Philosoph L, Roness H, Carmely A, Fishel-Bartal M, Ligumsky H, Paglin S, Wolf I, Kanety H, Sredni B \& Meirow D 2013 Cyclophosphamide triggers follicle activation and 'burnout'; AS101 prevents follicle loss and preserves fertility. Science Translational Medicine 5 185ra162. (https://doi.org/10.1126/scitranslmed.3005402)

Kano M, Sosulski AE, Zhang L, Saatcioglu HD, Wang D, Nagykery N, Sabatini ME, Gao G, Donahoe PK \& Pepin D 2017 AMH/MIS as a contraceptive that protects the ovarian reserve during chemotherapy. PNAS 114 E1688-E1697. (https://doi.org/10.1073/pnas.1620729114)

Kerr JB, Hutt KJ, Cook M, Speed TP, Strasser A, Findlay JK \& Scott CL 2012a Cisplatin-induced primordial follicle oocyte killing and loss of fertility are not prevented by imatinib. Nature Medicine 18 1170-172; author reply 1172-1174. (https://doi.org/10.1038/nm.2889)

Kerr JB, Hutt KJ, Michalak EM, Cook M, Vandenberg CJ, Liew SH, Bouillet P, Mills A, Scott CL, Findlay JK, et al. 2012b DNA damageinduced primordial follicle oocyte apoptosis and loss of fertility require TAp63-mediated induction of Puma and Noxa. Molecular Cell 48 343-352. (https://doi.org/10.1016/j.molcel.2012.08.017)

Kim SY, Cordeiro MH, Serna VA, Ebbert K, Butler LM, Sinha S, Mills AA, Woodruff TK \& Kurita T 2013 Rescue of platinum-damaged oocytes from programmed cell death through inactivation of the p53 family signaling network. Cell Death and Differentiation 20 987-997. (https:// doi.org/10.1038/cdd.2013.31)

Kim SY, Ebbert K, Cordeiro MH, Romero M, Zhu J, Serna VA, Whelan KA, Woodruff TK \& Kurita T 2015 Cell autonomous phosphoinositide 3-kinase activation in oocytes disrupts normal ovarian function through promoting survival and overgrowth of ovarian follicles. Endocrinology 156 1464-1476. (https://doi.org/10.1210/en.2014-1926)

Kim SY, Nair DM, Romero MM, Serna VA, Koleske AJ, Woodruff TK \& Kurita T 2018 Transient inhibition of p53 homologs protects ovarian function from two distinct apoptotic pathways triggered by anticancer therapies. Cell Death and Differentiation [epub]. (https://doi. org/10.1038/s41418-018-0151-2)

Kurita T, Cunha GR, Robboy SJ, Mills AA \& Medina RT 2005 Differential expression of p63 isoforms in female reproductive organs. Mechanisms of Development 122 1043-1055. (https://doi.org/10.1016/j. mod.2005.04.008) 
Letterie GS 2004 Anovulation in the prevention of cytotoxic-induced follicular attrition and ovarian failure. Human Reproduction 19 831-837. (https://doi.org/10.1093/humrep/deh120)

Ludeman SM 1999 The chemistry of the metabolites of cyclophosphamide. Current Pharmaceutical Design 5 627-643.

Madden JA, Hoyer PB, Devine PJ \& Keating AF 2014 Involvement of a volatile metabolite during phosphoramide mustard-induced ovotoxicity. Toxicology and Applied Pharmacology 277 1-7. (https://doi. $\operatorname{org} / 10.1016 /$ j.taap.2014.03.006)

Marcello MF, Nuciforo G, Romeo R, Di Dino G, Russo I, Russo A, Palumbo G \& Schiliro G 1990 Structural and ultrastructural study of the ovary in childhood leukemia after successful treatment. Cancer 66 2099-2104. (https://doi.org/10.1002/10970142(19901115)66:10<2099::AID-CNCR2820661010>3.0.CO;2-3)

Morita Y, Perez GI, Paris F, Miranda SR, Ehleiter D, Haimovitz-Friedman A, Fuks Z, Xie Z, Reed JC, Schuchman EH, et al. 2000 Oocyte apoptosis is suppressed by disruption of the acid sphingomyelinase gene or by sphingosine-1-phosphate therapy. Nature Medicine 6 1109-1114. (https://doi.org/10.1038/80442)

Paris F, Perez GI, Fuks Z, Haimovitz-Friedman A, Nguyen H, Bose M, Ilagan A, Hunt PA, Morgan WF, Tilly JL, et al. 2002 Sphingosine 1-phosphate preserves fertility in irradiated female mice without propagating genomic damage in offspring. Nature Medicine 8 901-902. (https://doi.org/10.1038/nm0902-901)

Peng KW, Myers R, Greenslade A, Mader E, Greiner S, Federspiel MJ, Dispenzieri A \& Russell SJ 2013 Using clinically approved cyclophosphamide regimens to control the humoral immune response to oncolytic viruses. Gene Therapy 20 255-261. (https://doi. org/10.1038/gt.2012.31)

Perez GI, Knudson CM, Leykin L, Korsmeyer SJ \& Tilly JL 1997 Apoptosisassociated signaling pathways are required for chemotherapymediated female germ cell destruction. Nature Medicine 3 1228-1232. (https://doi.org/10.1038/nm1197-1228)

Perez GI, Robles R, Knudson CM, Flaws JA, Korsmeyer SJ \& Tilly JL 1999 Prolongation of ovarian lifespan into advanced chronological age by Baxdeficiency. Nature Genetics 21 200-203. (https://doi.org/10.1038/5985)

Petrillo SK, Desmeules P, Truong TQ \& Devine PJ 2011 Detection of DNA damage in oocytes of small ovarian follicles following phosphoramide mustard exposures of cultured rodent ovaries in vitro. Toxicology and Applied Pharmacology 253 94-102. (https://doi.org/10.1016/j. taap.2011.03.012)

Phan CN, Wilkinson M, Cohen MB, Dunn S \& Carroll P 1994 Primary osteogenic sarcoma of the urinary bladder successfully treated with combination therapy. Urology 44 771-774. (https://doi.org/10.1016/ S0090-4295(94)80228-9)

Rinaldi VD, Hsieh K, Munroe R, Bolcun-Filas E \& Schimenti JC 2017 Pharmacological inhibition of the DNA Damage checkpoint prevents radiation-induced oocyte death. Genetics 206 1823-1828. (https://doi. org/10.1534/genetics.117.203455)

Roness H, Gavish Z, Cohen Y \& Meirow D 2013 Ovarian follicle burnout: a universal phenomenon? Cell Cycle 12 3245-3246. (https://doi. org/10.4161/cc.26358)

Soleimani R, Heytens E, Darzynkiewicz Z \& Oktay K 2011 Mechanisms of chemotherapy-induced human ovarian aging: double strand DNA breaks and microvascular compromise. Aging 3 782-793. (https://doi. org/10.18632/aging.100363)

Suh EK, Yang A, Kettenbach A, Bamberger C, Michaelis AH, Zhu Z, Elvin JA, Bronson RT, Crum CP \& McKeon F 2006 p63 protects the female germ line during meiotic arrest. Nature 444 624-628. (https:// doi.org/10.1038/nature05337)

Takamizawa A, Matsumoto S, Iwata T, Tochino Y, Katagiri K \& Yamaguchi K 1975 Studies on cyclophosphamide metabolites and their related compounds. 2. Preparation of an active species of cyclophosphamide and related compounds. Journal of Medicinal Chemistry 18 376-383. (https://doi.org/10.1021/jm00238a011)

Thorbinson C, Oni L, Smith E, Midgley A \& Beresford MW 2016 Pharmacological management of childhood-onset systemic lupus erythematosus. Pediatric Drugs 18 181-195. (https://doi.org/10.1007/ s40272-016-0170-8)

Tuppi M, Kehrloesser S, Coutandin DW, Rossi V, Luh LM, Strubel A, Hotte K, Hoffmeister M, Schafer B, De Oliveira T, et al. 2018 Oocyte DNA damage quality control requires consecutive interplay of CHK2 and CK1 to activate p63. Nature Structural and Molecular Biology 25 261-269. (https://doi.org/10.1038/s41594-018-0035-7)

Van der Steen J, Timmer EC, Westra JG \& Benckhuysen C 1973 4-hydroperoxidatin in the Fenton oxidation of the antitumor agent cyclophosphamide. Journal of the American Chemical Society 95 7535-7536. (https://doi.org/10.1021/ja00803a070)

Received in final form 9 October 2018

Accepted 26 October 2018 (c) 2019 Society for Endocrinology Published by Bioscientifica Ltd. Printed in Great Britain 